\title{
ĐÁNH GIÁ KẾT QUẢ SỬ DỤNG LASER Nd-YAGMỞ BAO SAU TẠI BỆNH VIỆN MẮT HÀ NAM
}

Vũ Tuấn Anh1, Ngụy Cao Phi², Phạm Trọng Văn 3

\begin{abstract}
TÓM TẮT.
Mục tiêu: 1, Đánh giá kết quả mở bao sau bằng laser Nd-YAG tại Bệnh viện Mắt Hà Nam 2, Nhận xét 1 số yếu tố liên quan. Đối tượng và PPNC: can thiệp lâm sàng trên mắt đục bao sau sau mô thể thủy tinh, đánh giá kết quả cải thiện thị lực và biến chứng. Kết quả: 50 mắt (43 bênh nhân tuổi trung bình 73,73 tuổi (4899) bị đục bao sau sau mổ phaco đặt thể thủy tinh nhân tạo (IOL) thời gian 42,96 $\pm 21,94$ tháng đã được mở bao sau bằng laser Nd-YAG, thị lực (TL) tăng trung bình 4,68 $\pm 1,56$ hàng, không có biến chứng đáng kể xảy ra. Kết luận: laser Nd-YAG là kỹ thuật an toàn, hiệu quả trong điêu trị đục bao sau thứ phát sau mổ đục thể thủy tinh tại đơn vị chăm sóc mắt tuyến tỉnh.

Tư khóa: đục bao sau, laser Nd-YAG
\end{abstract}

\section{SUMMARY \\ OUTCOMES OF Nd-YAG POSTERIOR} CAPSULOTOMYIN HANAM EYE HOSPITAL

Purposes: 1, Clinical assessment of Nd-YAG capsulotomy result in Hanam Eye Hospital 2, Investigate some related - factors with final result. opacification - laser treatment. Materials and Method: interventional case series, 50 PCO eyes (43 patients) were capsulotomy. Results: visual outcome was improved $4.86 \pm 1.56$ lines, no complication. Conclusion: laser Nd-YAG capsulotomy is safe, effectiveness technique and can implemente at provincial level. Nd-YAG

Keywords: posterior capsule opacification, laser

\section{I. ĐĂT VẤN ĐỀ}

Đục bao sau thể thủy tinh (TTT) là một biến chứng phổ biến sau phẫu thuật đục TTT, ảnh hưởng đến chức năng thị giác: giảm thị lực $(T L)$, dễ bị chói lóa thậm chícó thể gây song thị một mắt $t^{1,2}$. Mở bao sau bằng laser Nd-YAG là phương pháp hiệu quả về kinh tế và an toàn ${ }^{2}$, được thực hiện trên thế giới từ hơn 30 năm, và được sử dụng rộng rãi tại các trung tâm nhãn khoa lớntrên toàn quốc.

Đã có một số đề tài nghiên cứu trong nước về điều trị đục bao sau TTT bằng laser Nd - YAG cho thấy kết quả điều trị rất khả quan. Tại Bệnh

\footnotetext{
${ }^{1}$ Bệnh viện Mắt Trung Ương

${ }^{2}$ Bệnh viện Mắt Hà Nam

${ }^{3}$ Trường Đại học Y Hà Nội

Chịu trách nhiệm chính: Vũ Tuấn Anh

Email: vta.oph@gmail.com

Ngày nhận bài: 8.4.2021

Ngày phản biện khoa học: 24.5.2021

Ngày duyệt bài: 7.6.2021
}

viên Mắt Hà Nam, kỹ thuât này đã được ứng dụng từ 2006, góp phần vào giải phóng mù lòa tại cộng đồng. Vì vậy, để đánh giá kết quả điêu trị, chúng tôi tiến hành nghiên cứu với 2 mục tiêu:

1. Đánh giá kết quả mở bao sau bằng laser Nd-YAGtrên mắt đã mổ có đặt thủy tinh thể nhân tạo tại bệnh viện Mắt Hà Nam.

2. Nhận xét 1 số yếu tố liên quanđến kết quả trong nhóm bệnh nhân nghiên cứu.

\section{II. ĐỐI TƯợNG VÀ PHƯƠNG PHÁP NGHIÊN CỨU}

Nghiên cứu can thiệp thử nghiệm lâm sàng được thực hiện tại Bệnh việnMắt Hà Namtừ tháng 9/2019 đến tháng 3/2020 trên 50 mắt (43 bệnh nhân).

Tiêu chuẩn lựa chọn: bệnh nhân đục bao sau trên mắt đãphẫu thuật đục TTT tuổi già có đặt IOL, TL sau chỉnh kính $\leq 20 / 40$.

Tiêu chuẩn loại trừ: bệnh nhân đang có bệnh viêm cấp tính tại mắt hoặc các bệnh lý khác ở mắt, mắt có nhãn áp(NA) cao, không đồng ý tham gia nghiên cứu.

Phương tiện sử dụng trong điêu trị laser

- Thuốc nhỏ giãn đồng tử Mydriacin 0,5\%, thuốc tê Alcain $1 \%$.

- Máy laser Nd-YAG bước sóng 1064 nm.

- Kính tiếp xúc Ocular Abraham Capsulotomy YAG Laser.

Xác định mức độ và hình thái đục bao sau sau khi nhỏ rãn đồng tử:

- Đánh giá mức độ đục bao sau: theo phân loại của Prajna N. V ${ }^{3}$ từ 0 đến 3

- Xác định hình thái đục bao sau: theo Bhargava R. ${ }^{4}$ gồm hình thái xớ, hình thái hạt trai Elschnig và hình thái hỗn hợp

- Thu thập các biến số trước và sau can thiệp ( $T L$, NA, biển chứng)

\section{KẾT QUẢ NGHIÊN CỨU}

50 mắt (43 bệnh nhân) được mở bao sau bằng laser tiến hà̀nh trong thời gian từ 9/2019 đến tháng 3/2020.

3.1. Đặc điểm vê tuổi và giới

Bảng 3.1. Đặc điểm nhóm tuổi $(n=43)$

\begin{tabular}{|c|c|c|}
\hline Nhóm tuối & $\mathbf{N}$ & $\mathbf{\%}$ \\
\hline$<60$ & 2 & 4.7 \\
\hline $60-69$ & 11 & 25.5 \\
\hline $70-79$ & 18 & 41.9 \\
\hline$\geq 80$ & 12 & 27.9 \\
\hline Tống & $\mathbf{4 3}$ & $\mathbf{1 0 0}$ \\
\hline
\end{tabular}


Trong nghiên cứu này cho thấy tuổi trung bình 73,77 (48-92). Tuổi trung bình và phân bố nhóm tuổi là khác nhau trong các nghiên cứu của các tác giả khác nhau.Nghiên cứu của Phạm Thị Kim Thanh ${ }^{5}$ (2004) cũng cho thấy nhóm 70 79 tuổi chiếm đa số $5(62,7 \% \%)$. Gần đây nhất là nghiên cứu của Nguyễn Mạnh Hải ${ }^{6}$ (2019) cho thây tnhóm 70-80 tuổi chiếm nhiều nhất $(46,8 \%)$. Nhóm tuổi bệnh nhân cần can thiệp phần nào cho thấy xu hướng già hóa dân số cũng như nhu cầu chăm sóc sức khỏe của người cao tuổi ở Viêt Nam.

Phân bố bệnh nhân theo giới. Số bệnh nhân nữ (32 người chiếm 64\%) nhiều hơn rất nhiều số bệnh nhân nam (11 chiếm 22\%).Xu hướng cao hơn ở nhóm nữ là phù hợp với tỷ lệ mắc bệnh đục TTT ở nữ cao hơn nam. Kết quả về giới cũng gần với nhận định của Nguyễn Mạnh Hảítỷ lệ bệnh nhẩn nữ chiếm 70,1\% nhiều hơn số bệnh nhân nam chiếm $29,9 \%$.

3.2. Đặc điểm lâm sàng và kêt quả mở bao sau

3.2.1. Đặc điểm lâm sàng

Triệu chứng chủ quan

Bảng 3.2. Triệu chứng chủ quan tại mắt $(n=50)$

\begin{tabular}{|c|c|c|}
\hline Lý do vào viện & $\mathbf{N}$ & $\mathbf{\%}$ \\
\hline Nhìn mờ & 48 & 96 \\
\hline Chói sáng & 2 & 4 \\
\hline Tống & $\mathbf{5 0}$ & $\mathbf{1 0 0}$ \\
\hline
\end{tabular}

Đa số bênh nhân đến vì lí do nhìn mờ với 48 mắt $(96 \%)$, chỉ có 2 mắt đến vì cảm giác chói sáng $(4 \%)$. Nghiên cứu của các tác giả khác cũng cho thây nhóm bệnh nhân đến khám chủ yếu vì nhìn mờ. Trong nghiên cứu của Nguyễn Mạnh Hải ${ }^{6}$ (2019) nhóm bệnh nhân có biểu hiện nhìn mờ chiếm $96,4 \%$.

Thời gian sau phẫu thuật đục thể thủy tinh

Bảng 3.3. Thời gian sau phẫu thuật đục thể thưy tinh $(n=50)$

\begin{tabular}{|c|c|c|c|}
\hline Thời gian & $\mathbf{N}$ & $\%$ & $\mathbf{P}$ \\
\hline$\leq 12$ tháng & 3 & 6 & \multirow{6}{*}{$<0,05$} \\
\hline$>12-24$ tháng & 7 & 14 & \\
\hline$>24-36$ tháng & 7 & 14 & \\
\hline$>36-48$ tháng & 15 & 30 & \\
\hline$>48$ tháng & 18 & 36 & \\
\hline Tống & 50 & 100 & \\
\hline Trung bình & & $\begin{array}{l}96 \pm 21 \\
g-90\end{array}$ & \\
\hline
\end{tabular}

Kết quả nghiên cứu cho thâyy thời gian sau

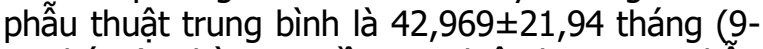
90 tháng). Thời gian cần can thiệp laser sau phấu thuâat TाT là gần tương đương so với các tác giả trên thế giới ${ }^{2,3,4}$, chứng tỏ chất lượng phẫu thuật TाT đã có tiến bộ rõ rệt. Tuy vậy, đục bao sau ngoài kỹ thuật mổ còn phụ thuộc rất nhiều yếu tố như tuổi phẫu thuâtt, loại bệnh lý đục TT, bệnh lý khác tại mắt, bệnh lý toàn thân ${ }^{3}$.

Chức năng trước phẫu thuật

Thị lực trước laser

Bảng 3.4. Thị lực trước điều trị laser $(n=50)$

\begin{tabular}{|c|c|c|c|}
\hline Thị lực & $\begin{array}{c}\text { Số } \\
\text { lượng }\end{array}$ & $\begin{array}{c}\text { Tỷ lệ cộng } \\
\text { dônn }\end{array}$ \\
\hline ĐNT $<3 \mathrm{~m}$ & 8 & 16 & 16,0 \\
\hline ĐNT $3 \mathrm{~m}-<20 / 200$ & 14 & 28 & 44,0 \\
\hline $20 / 200-<20 / 70$ & 28 & 66 & 100 \\
\hline Tống & $\mathbf{5 0}$ & $\mathbf{1 0 0}$ & $\mathbf{1 0 0}$ \\
\hline
\end{tabular}

Thị lực của nhóm đối tượng trong nghiên cứu từ dưới ĐNT3m đến<20/70. Trong đó <20/200: 22 mắt $44(\%), 20 / 200-<20 / 70: 28$ mắt $(66 \%)$. Trong nghiên cứu này, những mắt có TL $>20 / 200$ vẫn được chỉ định điều trị laser do bệnh nhân trước đó có cảm giác chói sáng, ảnh hưởng tới chất lượng thị giác. Đây là lý do mà bênh nhân phàn nàn nhiều và là lý do chính khiến bệnh nhân đến khám mắt.

3.1.2. Kết quả đục bao sau thứ phát sau mổ đặt IOL

Tỷ lệ, mức độ và hình thái đục bao sau TTा

Bảng 3.5. phân bố số mắt đục bao sau theo hình thái và mức độ đục

\begin{tabular}{|c|c|c|c|c|c|}
\hline Hình thái & Độ 1 & Độ 2 & Độ 3 & Tống & Tỷ lệ \\
\hline Dạng Xơ hóa & 5 & 35 & 6 & 46 & 92,0 \\
\hline Dạng Hat trai & 0 & 1 & 0 & 1 & 2,0 \\
\hline Dạng Hồn hợp & 0 & 1 & 2 & 3 & 6,0 \\
\hline Tổng & $5(10,0 \%)$ & $37(74,0 \%)$ & $8(16,0 \%)$ & $50(100 \%)$ & $100 \%$ \\
\hline P & \multicolumn{5}{|c|}{$<0,05$} \\
\hline
\end{tabular}

Trong nghiên cứu của chúng tôi có đục độ 1: $5(10,0 \%)$; độ 2: $37(74,0 \%)$; độ 3: $8(16,0 \%)$. Về hình thái đục, số mắt đục xơ hóa chiếm chủ yếu: 46 mắt $(92,0 \%)$; hạt trai: 1 mắt $(2,0 \%)$; hốn hợp: 3 mắt $(6,0 \%$, ). Dạng xớ hóa chiếm ưu thế ở nhóm đục độ 3 có ý nghĩ̃a với $p<0,05$.

Hình thái đục xơ hóa là các tế bào biểu mô TTT còn sót lại vẩn dính vào bao trước, các tế bào này đóng vai trò ưu thế trong việc hình thành màng xơ trong khoảng thời gian từ 2 đến 6 tháng sau phẫu thuật , có thể tránh được biên chứng đục dạng này với kỹ thuật đánh bóng bao trước một cách cẩn thận ${ }^{3}$. 


\subsection{Kết quả mở bao sau}

3.3.1.Yếu tố liên quan và kết quả lâm sàng

Bảng 3.6. Kêt quả thị lực ở các thời điểm sau laser

\begin{tabular}{|c|c|c|c|c|c|}
\hline \multirow{2}{*}{ Thị lực } & \multicolumn{2}{|c|}{ Tăng } & \multicolumn{2}{c|}{ Giảm } & Không đối \\
\cline { 2 - 6 } Thời điểm & $\begin{array}{c}\text { Số mất } \\
(\%)\end{array}$ & $\begin{array}{c}\text { Số dòng trung } \\
\text { bình (mức độ) }\end{array}$ & $\begin{array}{c}\text { Số măt } \\
\mathbf{( \% )}\end{array}$ & $\begin{array}{c}\text { Số dòng trung } \\
\text { bình (mức độ) }\end{array}$ & Số mắt \\
\hline 1 ngày & $48(96,0 \%)$ & $3,37 \pm 1,55(1-6)$ & 0 & 0 & $2(4,0 \%)$ \\
\hline 1 tuần & $50(100 \%)$ & $4,47 \pm 1,53(1-7)$ & 0 & 0 & 0 \\
\hline 1 tháng & $50(100 \%)$ & $4,65 \pm 1,52(1-7)$ & 0 & 0 & 0 \\
\hline 3 tháng & $50(100 \%)$ & $4.68 \pm 1,56(1-7)$ & 0 & 0 & 0 \\
\hline
\end{tabular}

Bảng 3.7. Mức độ cải thiện TL ở thời điểm 3 tháng

\begin{tabular}{|c|c|c|c|}
\hline \multicolumn{2}{|c|}{ Đục bao sau } & $\begin{array}{c}\text { Số dòng thị } \\
\text { lực tăng }\end{array}$ & P \\
\hline \multirow{2}{*}{$\begin{array}{c}\text { Hình } \\
\text { thái } \\
\text { đục }\end{array}$} & Xơ hóa & $4,5 \pm 1,6$ & \multirow{2}{*}{$\mathrm{P}=0.37$} \\
\cline { 2 - 3 } & Hạt trai & $4,5 \pm 0$ & $\mathrm{p}>0.05$ \\
\cline { 2 - 3 } Hồn hợp & $5,8 \pm 0,6$ & \\
\hline \multirow{3}{*}{ Độ đục } & Độ̣ & $3.5 \pm 2,1$ & \multirow{3}{*}{$\mathrm{P}=0.22$} \\
\cline { 2 - 3 } & Độ 2 & $4.7 \pm 1,5$ & \\
\cline { 2 - 3 } & Độ 3 & $4.4 \pm 1,6$ & \\
\hline
\end{tabular}

Ơ thời điểm 3 tháng sau laser hình thái đục

hạt trai có số dòng tăng nhiêu nhất $(3,96 \pm$ 1,48 dòng), tiếp theo là hình thái hỗn hợp $(3,57$ $\pm 1,41)$ thấp nhất là hình thái đục xơ hóa $(3,69$ $\pm 1,21)$. Khác biệt không có ý nghĩa thống kê.

Theo độ đục, số dòng TL tăng ở đục độ 2 là cao nhất $(4.7 \pm 1,5$ dòng), tiếp theo là đục đô 3

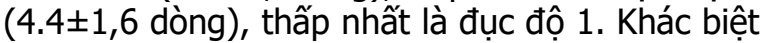
không có ý nghĩa thống kê.

So sánh tỷ lệ mắt có TL được cải thiên theo nghiên cứu của chúng tôi cũng cho kết quả tương tự nghiên cứu của Nguyễn Mạnh Hải ${ }^{11}$ (2019): 98,8\%

Bảng 3.8. Nhãn áp tại các thời điểm

\begin{tabular}{|c|c|c|c|c|c|c|}
\hline $\begin{array}{c}\text { Thời } \\
\text { điểm } \\
\text { Nhãn áp }\end{array}$ & $\begin{array}{c}\text { Trước } \\
\text { Laser } \\
(\mathbf{n = 5 0 )}\end{array}$ & $\begin{array}{c}\text { Sau } 1 \text { giờ } \\
(n=50)\end{array}$ & $\begin{array}{c}\text { Sau } 1 \text { ngày } \\
(n=50)\end{array}$ & $\begin{array}{c}\text { Sau } 1 \\
\text { tuân } \\
(n=50)\end{array}$ & $\begin{array}{l}\text { Sau } 1 \\
\text { tháng } \\
(n=50)\end{array}$ & $\begin{array}{l}\text { Sau } 3 \\
\text { tháng } \\
(n=50)\end{array}$ \\
\hline Trung bình & $19,0 \pm 1,1$ & $19,2 \pm 1,2$ & $19,1 \pm 1,1$ & $19,1 \pm 1,1$ & $19,0 \pm 1,1$ & $19,0 \pm 1,1$ \\
\hline Giới hạn & $18-21$ & $18-22$ & $18-21$ & $18-21$ & $18-21$ & $18-21$ \\
\hline $\mathrm{P}$ & & $<0,05$ & & & $>0,05$ & \\
\hline
\end{tabular}

Trong nghiên cứu của chúng tôi NA trung bình sau $1 \mathrm{~h}$, sau 1 ngày có tăng so với trước laser $(p<0,05)$. Sau laser 1 h có 1 mắt có hiện tượng tăng NA ở mức $24 \mathrm{mmHg}$. Sau 1 tuần, 1 tháng và 3 tháng tất cả 50 mắt $(100 \%)$ NA ổn định. NA không có thay đổi ở thời điểm sau 1 tuần, 1 tháng và 3 tháng $(p>0,05)$.

Tăng NA tạm thời là biến chứng phổ biến nhất. NA thường bắt đầu tăng sớm sau khi thực hiện laser, đạt đỉnh khoảng 3 giờ, trở về mức bình thường trong một tuần. Cơ chế tăng NA được giải thích do sự lắng đọng của các mảnh vụn tại vùng bè, nghển đồng tử, do phù viêm cơ thể mi hoặc chân mống mắt đi kèm đóng góc tiền phòng. Theo Bhargava R. ${ }^{4}(2015)$ sau laser $3 \mathrm{~h},>10 \%$ số mắt NA tăng $>10 \mathrm{mmHg}$ sau 1 ngày điều trị bằng Diamox đường uống và thuốc chẹn beta tại chố, chỉ còn $1 \%$ số mắt có tăng NA. Theo Nguyễn Quốc Đạt ${ }^{1}$ (2005) sử dụng Aprachlonidin $1 \%$ và Diamox $0,25 \mathrm{~g}$ kết quả không có biến chứng tăng NA. Theo Nguyễn Mạnh Hải ${ }^{6}$ (2007), sử dụng Timolol 0,5\% chỉ gặp 1 mắt có tăng NA sau điều trị 1 ngày .

Trong nghiên cứu tỷ lệ mắt có tăng NA là không đáng kể có thể do việc dùng thuốc điều trị dự phòng trước và sau laser cho tất cả các bệnh nhân:

Tổn thương trên IOL

Bảng 3.9.Tôn thương trên IOLtheo mức đô đuc

\begin{tabular}{|c|c|c|c|c|}
\hline $\begin{array}{c}\text { Noội } \\
\text { dung }\end{array}$ & Rỗ & $\begin{array}{c}\text { Không } \\
\text { biến chứng }\end{array}$ & Tổng & P \\
\hline Độ 1 & 0 & $5(100 \%)$ & $5(100 \%)$ & \\
\cline { 1 - 1 } Độ 2 & $3(8,1 \%)$ & $34(91,9 \%)$ & $37(100 \%)$ & $>0,05$ \\
\hline Độ 3 & $1(12,5 \%)$ & $7(87,5 \%)$ & $8(100 \%)$ & \\
\hline
\end{tabular}

Trong tất cả các mắt đã làm laser không có trường hợp nào bị rạn, võ IOL. Trong đó có 4 mắt $(8,0 \%)$ thấy xuất hiện ảnh hưởng đếnIOL ở dạng vết rố vùng chu biên, gặp ở mắt có đục độ 2 và độ 3 . Trong nhóm đục độ2có 3 mắt (chiếm $8,1 \%$ ) bị rỗ vùng chu biên, có 1 mắt trong nhóm đục độ 3 (chiếm 12,5\%). Tuy nhiên sự khác biệt này không có ý nghĩa thống kê $(p>0,05)$. Đục đồ 1 không có tổn hại IOL. Có 7 mắt $(8,3 \%)$ xuất hiện tổn hại dạng vết rỗ vùng chu biên, đây là những mắt đục độ 2 và 3 ; trong nhóm đục độ 2 có 4 mắt (chiếm $8,5 \%$ ) bị rỗ vùng chu biền, trong khi có 3 mắt trong nhóm đục độ 3 $(17,7 \%)$, tuy nhiên sự khác biệt không có ý 
nghĩa thống kê ( $p>0,05)$.

Theo thống kê của các nghiên cứu, ảnh hưởng đến IOL do laser Nd-YAG có thể xảy ra ở các mức độ khác nhau: nhe nhất và hay gặp nhất là những vết dạng rỗ, nặng hơn là rạn, và nặng nhất là vỡ IOL. Nguyên nhân gồm: mức nẳng lượng laser, mức độ đục bao sau, khoảng cách giữa IOL và bao sau TTT, chất liệu IOL. Trong nghiên cứu này, biến chứng ảnh hưởng IOL chỉ gặp ở dạng vết rỗ, không gặp các tổn thương nặng hơn như rạn hay vỡ. Các vết rỗ đều nằm ở vị trí ngoại vi khi mở bao sau theo đường mở hình tròn, cho nên sau khi điều trị đồng tử co lại bình thường, mống mắt che khuất các vết rỗ, không làm ảnh hưởng đến chức năng thị giác của bệnh nhân sau điêu trị. Tỷ lệ ảnh hưởng tới IOL trong nghiên cứu của chúng tôi thấp hơn kết quả của một số tác giả. Nguyễn Quốc Đạt (2005) là $51,4 \%$, nghiên cứu của Nguyễn Quý Đông (2007) là 43,6\%. Tỷ lệ này trong nghiên cứu thấp hơn có thể do đặc điểm của IOL trong nghiên cứu, $100 \%$ bệnh nhân được phẫu thuật phaco đặt loại IOL gấp được (foldable), chất liệu acrylic kị nước, còn đối tượng nghiên cứu của 2 tác giả trên được thực hiện cả mắt được đặt IOL có chất liệu PMMA dễ tổn thương hơn.

\begin{tabular}{|} 
Bảng 3.10. Các biến chứng khác \\
\begin{tabular}{|c|c|c|c|}
\hline Biến \\
chứng
\end{tabular} & $\begin{array}{c}\text { Số } \\
\text { lượng }\end{array}$ & $\%$ & Đặc điểm \\
\hline Viêm MBĐ & 1 & 2,0 & $\begin{array}{c}\text { VMBĐ trước, } \\
\text { xuất hiện 1 ngày } \\
\text { sau laser và ồn } \\
\text { định sau 1 tuần } \\
\text { điêu trị }\end{array}$ \\
\hline $\begin{array}{c}\text { Đục dịch } \\
\text { kính }\end{array}$ & 11 & 22,0 & $\begin{array}{c}\text { Xuất hiện trong } \\
\text { và sau laser }\end{array}$ \\
\hline $\begin{array}{c}\text { Phù hoàng } \\
\text { điểm dạng } \\
\text { nang }\end{array}$ & 0 & 0 & \\
\hline $\begin{array}{c}\text { Xuất huyết } \\
\text { tiền phòng }\end{array}$ & 0 & 0 & \\
\hline
\end{tabular}

Đục dịch kính phát sinh trong quá trình điều trị là do mảng bao sau lơ lửng trong buông dịch kính, không tính những mắt đã được phát hiện trước laser.

Viêm màng bồ đào theo kết quả của Nguyễn Quốc Đạt (2005) là 2,2\%, của Nguyễn Quý Đông (2007) là 4,3\% ${ }^{9}$, Khan và cộng sự (2014) là $1,14 \%{ }^{6}$. Trong nghiên cứu của chúng tôi, kết quả có tính tương đồng, các bệnh nhân được điêu trị kháng viêm tại chô̂ và đều đáp ứng tốt.

3.3.2. Các thông số kĩ thuật laser và yếu tố liên quan

Trong 50 mắt được mở bao sau chỉ tiến hành kỹ thuật 1 lần, không có trường hợp nào phải tiến hành bổ sung lần hai. Năng lượng ban đầu từ $3 \mathrm{~mJ} / x u n g$, sau đó tăng dần đến đủ để phá được bao.

Năng lượng laser với mức độ đục bao sau

Bảng 3.11. Mức năng lượng với mức độ duc bao sau

\begin{tabular}{|c|c|c|c|}
\hline $\begin{array}{l}\text { Năng } \\
\text { lượng } \\
\text { Dộ đục }\end{array}$ & $\begin{array}{c}\text { Mức năng } \\
\text { lượng trung } \\
\text { bình/xung } \\
\text { (mj) }\end{array}$ & \begin{tabular}{|c|} 
Số xung \\
trung \\
bình \\
(lần) \\
\end{tabular} & $\begin{array}{c}\text { Tống } \\
\text { năng } \\
\text { lượng } \\
(\mathbf{m j})\end{array}$ \\
\hline $\begin{array}{c}\text { Độ 1 } \\
(\mathrm{n}=5)\end{array}$ & $2,8 \pm 0,4$ & $6,0 \pm 0,7$ & $16,8 \pm 3,4$ \\
\hline $\begin{array}{c}\text { Độ 2 } \\
(\mathrm{n}=37)\end{array}$ & $3,0 \pm 0,2$ & $6,3 \pm 1,0$ & $19,3 \pm 3,4$ \\
\hline $\begin{array}{c}\text { Độ } 3 \\
(\mathrm{n}=8)\end{array}$ & $3,1 \pm 0,4$ & $7,1 \pm 1,8$ & $22,1 \pm 5,3$ \\
\hline $\mathbf{P}$ & & $<0.05$ & \\
\hline
\end{tabular}

Độ đục càng cao thì mức năng lượng sử dụng càng lớn $(p<0,005)$.

Mức năng lượng với hình thái đục

Bảng 3.12. Mức năng lượng với hinh thái đục bao sau

\begin{tabular}{|c|c|c|c|}
$\begin{array}{r}\text { Năng } \\
\text { Yượg }\end{array}$ & $\begin{array}{c}\text { Mức năng } \\
\text { lượng trung } \\
\text { bình/xung } \\
\text { (mj) }\end{array}$ & $\begin{array}{c}\text { Số xung } \\
\text { trung } \\
\text { bình } \\
\text { (lấn) }\end{array}$ & $\begin{array}{c}\text { Tống } \\
\text { năng } \\
\text { lượng } \\
\text { (mj) }\end{array}$ \\
\hline Xơ hóa & $3,0 \pm 0,3$ & $6,37 \pm 1,0$ & $19,1 \pm 3,4$ \\
\hline Hạt trai & $3,0 \pm 0$ & $6,0 \pm 0$ & $18,0 \pm 0$ \\
\hline Hồn hợp & $3,0 \pm 0$ & $8,7 \pm 2,3$ & $26,0 \pm 6,9$ \\
\hline p & \multicolumn{3}{|c|}{$<\mathbf{0 , 0 1}$} \\
\hline
\end{tabular}

Tổng năng lượng trung bình trong nghiên cứu của chúng tôi với đục hạt trai và đục hồn hợp là cao hơn so với kết quả của Nguyễn Quốc Đạt $(2005)^{1}$, Bhargava ${ }^{4}$ (2015), nhưng ở đục dạng xơ hóa lại thấp hơn nhiều so với Nguyễn Quốc Đạt tuy nhiên khác biệt không nhiều so với kết quả của Bhargava (2015). Có thể do có sự khác nhau ở các nghiên cứu về mức độ, đặc điểm đục bao sau của nhóm đối tượng nghiên cứu.

\section{KẾT LUÂNN}

Nghiên cứu mở bao sau bằng laser Nd-YAG trên 50 mắt (43 bệnh nhân) tuổi trung bình 73,73 (48-99), thời giam can thiệp sau mổ là 42,96 $\pm 21,94$ tháng, TL cải thiện tối đa sau 1 tháng 4,68 $\pm 1,56$ hàng. Không có biến chứng đáng kể nào xảy ra. Tăng NA thoáng qua sau laser có thể xử trí bằng thuốc hạ NA đường uống. Kỹ thuật mở bao sau bằng laser Nd-YAG là kỹ thuật an toàn, hiệu quả, có thể thực hiện tại cơ sở chăm sóc mắt tuyến tỉnh, góp phần giải phóng mù lòa tại cộng đồng.

\section{TÀI LIỆ THAM KHẢO}

1. Nguyễn Quốc Đạt (2005), Nghiên cứu sử dụng 
Lasser Nd : YAG điều trị đục bao sau thứ phát sau phấu thuât đăt thể thủy tinh nhân tao hâuu phòng tại cộng đồng, Luận án tiến sĩ y học, Trường Đại học Y Hà Nội.

2. Vasavada A.R., Raj S.M., Shah G.D.,Nanavaty M.A. (2013), Posterior capsule opacification after lens implantation: incidence, risk factors and management, Expert Review of Ophthalmology, 8(2), 141- 149.

3. Prajna N. V ., Ellwein L. B., Selveraj S. Manjula K.,Kupfer C. (2000), The Madurai Intraocular Lens Study IV: Posterior Capsule Opacification, American Journal of Ophthalmology, 130(3), $304-309$.

4. Bhargava R., Kumar P., Phogat H.,Chaudhary K. P. (2015), Neodymium - Yttrium Aluminium
Garnet Laser Capsulotomy Energy Levels for Posterior Capsule Opacification, Journal of Ophthalmic and Vision Research, 10 (1), 37-42.

5. Phạm Thị Kim Thanh (2004). Nghiên cứu đục bao sau thể thủy tinh thứ phát sau phấu thuât đắt thể thủy tinh nhân tạo và biện pháp xử lý, Luận án tiến sĩ y hoc, Trường Đai hoc Y Hà Nôi.

6. Nguyển Mạnh Hải (2019), Đánh giá kết quả mở bao sau thế thủy tinh bằng laser Nd-YAG trên mắt mổ phaco có đăt kính nôi nhãn, Luận văn chuyên khoa II, Trường Đại học Y̛ Hà Nội.

7. Vyas V. J., Ahir L. D.,Ratna B. (2016), To Study the Visual Outcome After Nd:-YAG laser Posterior Capsulotomy, International Journal of Science and Research, 5(10), 55 - 57.

\section{ĐĂC ĐIỂM CHİ SỐ TIM CỔ CHÂN Ở BÊNH NHÂN ĐÁI THÁO ĐƯỜNG TYP 2 LOÉT BÀN CHÂN TẠI BỆNH VIỆN NộI TIẾT TRUNG ƯƠNG}

\section{TÓM TẮT}

Mục tiêu: Mô tả đặc điểm chỉ số mạch cổ chân (CAVI)ở bênh nhân đái tháo đường typ 2 loét bàn chân tại Bệnh viện Nội tiết Trung ương. Đối tượng và phương pháp nghiên cứu: Nghiên cứu mố tả cắt ngang 176 bệnh nhân đái tháo đường typ 2có loét bàn chân đáp ứng tiêu chuẩn lựa chọn vào nghiên cứu. Kết quả: Tuổi trung bình nhóm nghiên cứu là $61,99 \pm 11,11$. Nam nhiều hơn nữ (59,7\% và 40,3\%). Thời gian mắc bệnh trên 10 năm là $58,5 \%$. Trung bình CAVI bên phải là $9,41 \pm 2,72$; CAVI bên trái là $9,27 \pm 2,23$ và CAVI trung bình là $9,34 \pm 2,29$. Trung bình CAVI không liên quan đến giới tính $(p>0,05)$. Trung bình CAVI nhóm ĐTÐ có THA cao hơn nhóm ĐTÐ không THA $(9,85 \pm 2,15$ so với $8,37 \pm 2,25$, $\mathrm{p}<0,05)$. Kết luận: Trung bình CAVI ở bệnh nhân ĐTÐ có LBC tăng cao hơn bình thường. THA làm ảnh hưởng đến trung bình chỉ số CAVI.

Tư khóa: mạch cổ chân CAVI, đái tháo đường typ 2, loét bàn chân

SUMMARY

CHARACTERISTICS OF CARDIO-ANKLE VASCULAR INDEX IN PATIENTS WITH DIABETES MELLITUS TYPE 2 WITH FOOT ULCERS AT THE NATIONAL HOSPITAL OF ENDOCRINOLOGY

Objective: To characterize the Cardio-ankle

\footnotetext{
${ }^{1}$ Bênh viên Nôi tiết trung ương

${ }^{2}$ Học viện Quân Y

${ }^{3}$ Dai hoc Y Hà Nôi

Chịu trách nhiệm chính: Bùi Thế Long

Email: bslong80@gmail.com

Ngày nhận bài: 9.4.2021

Ngày phản biện khoa học: 25.5.2021

Ngày duyệt bài: 9.6.2021
}

\section{Bùi Thế Long1, Đoàn Văn Đệㄹㄹ Bùi Mỹ Hạnh ${ }^{3}$}

vascular index (CAVI) in patients with type 2 diabetes with foot ulcers at Hospital of Endocrinology. Study object and method: A cross-sectional descriptive study of 176 patients with diabetes mellitus type 2 with foot ulcers who met the inclusion criteria for the study. Results: The mean age of the study group was $61.99 \pm 11.11$. More men than women $(59.7 \%$ and $40.3 \%)$. The disease duration over 10 years is $58.5 \%$. The mean CAVI on the right is $9.41 \pm 2.72$; The left CAVI was $9.27 \pm 2.23$ and the mean CAVI was $9.34 \pm 2.29$. Mean CAVI was not related to sex $(p>0.05)$. The mean CAVI in the diabetic group with hypertension was higher than that in the nonhypertensive group $(9.85 \pm 2.15$ compared with 8.37 \pm 2.25 , $p<0.05)$. Conclusion: Average CAVI in patients with type 2 diabetes with foot ulcers increased higher than normal. Hypertension affects the mean CAVI.

Key words: Cardio-ankle vascular index, type 2 diabetes, foot ulcers

\section{I. ĐĂT VẤN ĐỀ}

Đái tháo đường (ĐTĐ) týp 2 là môt bênh nôi tiết - chuyển hóa thường gặp, tỷ lệ mắc đái tháo đường ngày càng gia tăng. Một trong các biến chứng có thể gây tàn phế cho người bệnh là biến chứng bàn chân đái tháo đường. Chỉ số tim - cổ chân (Cardio-Ankle Vascular Index - CAVI) là một chỉ số đánh giá độ cứng của mạch máu dựa trên nguyên lý của vận tốc lan truyền sóng mạch (PWV). Nhiều tác giả trên thế giới khuyến cáo sử dụng CAVI trên lâm sàng để khảo sát, sàng lọc và theo dõi xơ vữa động mạch đặc biệt ở những bệnh nhân nguy cơ cao như Đái tháo đường typ 2[1]. Ở Việt Nam những năm gần đây đã có một số nghiên cứu về chỉ số CAVI trên những nhóm bệnh nhân có bệnh lý tim mạch 